\title{
Availability of Resources for After-Hours Surgical Management of Eye Injuries
}

\author{
Tina H. Chen, $\mathrm{MD}^{1,2}$ Kathryn A. Colby, MD, $\mathrm{PhD}^{1,2}$ Sarah Hilkert Rodriguez, MD, MPH ${ }^{1,2}$ \\ Mark B. Slidell, MD² Jessica J. Kandel, MD² Hassan A. Shah, MD ${ }^{1,2}$
}

\author{
${ }^{1}$ Department of Ophthalmology and Visual Science, University of \\ Chicago Medical Center, Chicago, Illinois \\ 2 Section of Pediatric Surgery, Department of Surgery, Comer \\ Children's Hospital, Chicago, Illinois
}

J Acad Ophthalmol 2018;10:e92-e97.

\begin{abstract}
Address for correspondence Hassan A. Shah, MD, Department of Ophthalmology and Visual Science, University of Chicago Medical Center, 5841 S. Maryland Avenue, MC 2114, Chicago, IL 60637 (e-mail: hshah1@bsd.uchicago.edu).
\end{abstract}

\author{
Abstract \\ Keywords \\ - after-hours eye \\ surgeries \\ - ocular trauma \\ - operating room \\ resources \\ - clinician satisfaction \\ - survey \\ - listserv
}

Background Approximately 2.4 million eye injuries per year occur in the United States. Because of the complexity of these injuries, many of these cases present to academic institutions. Ophthalmology residency programs have a wide range of resources available for eye injuries requiring after-hours surgical intervention.

Purpose The purpose of this study was to determine availability of resources for afterhours eye surgery and their effect on clinician satisfaction.

Methods Association of University Professors of Ophthalmology (AUPO) program directors were surveyed to assess the availability of eye-trained operating room (OR) nurses, functional operating microscopes, and suitable surgical supplies. The primary outcome measure was the availability of resources for after-hours eye surgery. Secondary outcome measures included the impact of resources on clinician satisfaction.

Results Fifty-seven program directors completed the survey. Most programs operated at level 1 trauma centers (95\%), had access to a functional microscope (95\%), and had frequent adequate surgical supplies (88\%). On the other hand, only $28(49 \%)$ programs reported consistent access to OR nurses with ophthalmologic training. Clinician satisfaction scores were three times higher for programs with frequent access to trained surgical OR staff than for programs without $(p<0.001)$.

Conclusion Approximately half of programs report consistent access to ophthalmologic-trained OR staff after hours. In contrast, most programs report access to a functional microscope and surgical supplies. The results of this survey suggest that directing resources toward improving access to after-hours staffing with specialty OR staff may improve clinician satisfaction.
Training in the management of ocular trauma is an Accreditation Council for Graduate Medical Education (ACGME) requirement for ophthalmology residency programs. Many residency programs provide training in both adult and pediatric eye disease. In the United States, approximately 2.4 million eye injuries occur per year. ${ }^{1}$ Approximately onethird of eye-related emergency room complaints are for

received

March 19, 2018

accepted after revision

June 4, 2018
DOI https://doi.org/

10.1055/s-0038-1666849. ISSN 2475-4757. ocular injuries. ${ }^{2}$ Ocular and adnexal injuries often require emergent or urgent surgical intervention within 24 or 72 hours, respectively. These include eyelid lacerations with canalicular involvement, intraocular foreign bodies, full-thickness corneal-scleral lacerations with or without uveal prolapse, and orbital fractures with extraocular muscle entrapment. Many of these cases require surgical
Copyright $\odot 2018$ by Thieme Medical Publishers, Inc., 333 Seventh Avenue, New York, NY 10001, USA. Tel: +1(212) 584-4662.
License terms

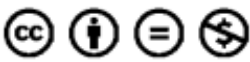


intervention after normal working hours due to the urgency of surgical intervention or the availability of the surgeon and operating rooms (ORs).

The specialized care needed for eye injuries and the availability of after-hours ophthalmological services result in many of these cases being managed at hospitals affiliated with ophthalmology training programs. These hospitals may or may not be level 1 trauma centers. Minimum criteria of patient care resources at trauma centers in the United States are typically mandated by the American College of Surgeons (ACS) or by state trauma guidelines. However, in regard to ophthalmology services, the ACS guidelines state that "Level 1 facilities are prepared to manage the most complex trauma patients and must have available a full spectrum of surgical specialists, including ... ophthalmology," but do not further specify minimum ophthalmology criteria. ${ }^{3}$ Ophthalmology residency programs tend to have a wide range of resources available for after-hours ophthalmic surgery, including on-call trainees, which may both promote access and affect the quality and efficiency of care delivered. To date, no study has attempted to evaluate the range of these resources available for ophthalmology residency programs across the United States.

The purpose of this article is to determine the availability of resources for after-hours eye surgeries at ACGME-accredited ophthalmology programs in the United States. We also sought to quantify clinician satisfaction based on the availability of resources, and to determine the most significant barrier to clinician satisfaction.

\section{Methods}

\section{Institutional Review Board Approval}

This project was a quality improvement study and was exempted from Institutional Review Board review.

\section{Data Collection}

An anonymous online survey was constructed on SurveyMonkey (-Fig. 1). The survey consisted of multiple-choice questions addressing the availability of three resources considered essential to high-quality surgical management of eye injuries: (1) OR staff specifically trained to assist in ocular cases, (2) a functional operating microscope, and (3) adequate surgical supplies. Multiple-choice response options regarding availability were "Almost always," "Frequently," "Infrequently," and "Almost never." The survey also included one question regarding overall clinician satisfaction with after-hours surgical management, and one question asking which resource (or lack thereof) most affected clinician satisfaction. The initial survey was sent in May 2017 to all ophthalmology residency program directors on an Association of University Professors of Ophthalmology (AUPO) listserv (eyepd.net). Follow-up reminder emails were then sent 1 and 3 weeks after the initial survey was sent.

\section{Outcomes}

The primary outcome measure was the availability of resources. Secondary outcomes assessed the impact of avail- able resources on clinician satisfaction. Satisfaction was graded on a scale of 1 to 10 . Predictors of clinician satisfaction (level 1 trauma center, cases per month, access to a functional microscope, supplies, and eye-trained OR nurses) were evaluated as dichotomous variables: frequently ("almost always" and "frequently") or infrequently ("infrequently or "almost never"), and cases were evaluated as fewer or more than five cases per month.

\section{Statistical Analysis}

Statistical analysis was performed using Stata version 1 (StataCorp LP, College Station, Texas, United States). Percentages were calculated with available resources. Median and interquartile range (IQR) were reported for clinician satisfaction scores, and $p$-values were calculated using the Wilcoxon rank-sum test. A generalized linear regression model was used to evaluate the impact of available resources on clinician satisfaction scores. The threshold for statistical significance was set at $p \leq 0.05$.

\section{Results}

\section{Access to Level 1 Trauma Services}

Fifty-seven of the 116 programs (49\%) completed the survey. Fifty-four of the 57 respondents (95\%) had access to either an adult or pediatric level 1 trauma, and forty-five (79\%) respondents had access to both adult and pediatric level 1 trauma hospitals. Seven programs (12\%) reported access to an adult level 1 trauma hospital only, while two programs (4\%) reported access to a pediatric level 1 trauma hospital only, and three programs (5\%) reported access to neither adult nor pediatric level 1 trauma hospitals. The majority of programs (63\%) performed more than five trauma cases per month.

\section{Availability of Resources}

Fifty-four of 57 (95\%) respondents reported access to a functioning microscope almost always or frequently, and 50 of $57(88 \%)$ respondents reported access to adequate surgical supplies almost always or frequently. However, 28 of 57 (49\%) programs reported access to eye-trained OR staff almost always or frequently. The remaining 29 of 57 (51\%) programs reported access to such OR staff either infrequently or almost never (-Fig. 2 ).

\section{Clinician Satisfaction}

The median satisfaction score among all programs was 6 (IQR: 5-8). Scores were significantly higher among programs with frequent access to eye-trained OR staff compared with programs with infrequent access to trained OR staff $(p<0.001)$. Similarly, scores were significantly higher for programs with access to surgical supplies $(p<0.001)$ and a functional microscope $(p=0.021)$ than for programs without these resources ( $\boldsymbol{- T a b l e ~} \mathbf{1}$ ).

Most programs had access to a functional microscope and adequate surgical supplies. In contrast, only half had access to eye-trained OR staff. No program with access to eyetrained OR staff lacked a microscope, and only one program with access to eye-trained OR staff lacked surgical supplies. 
1. Does your program currently involve a level 1 trauma center?
a. No
b. Yes, adult level 1 trauma only
c. Yes, pediatric level 1 trauma only
d. Yes, both adult and pediatric level 1 trauma

2. In which region is your institution?

a. Midwest (Illinois, Indiana, Iowa, Kansas, Michigan, Minnesota, Missouri,

Nebraska, North Dakota, Ohio, South Dakota, Wisconsin)

b. East coast (Connecticut, Massachusetts, Maine, New Hampshire, New York, Rhode Island, Vermont)

c. Mid-Atlantic (Delaware, Maryland, New Jersey, North Carolina, Pennsylvania, Virginia)

d. Southeast (Alabama, Arkansas, Florida, Georgia, Kentucky, Louisiana, Mississippi, South Carolina, Tennessee, West Virginia)

e. Southwest (Arizona, Colora do, Nevada, New Mexico, Oklahoma, Texas, Utah)

f. Pacific west (Alaska, California, Hawaii, Idaho, Montana, Oregon, Washington, Wyoming)

3. Approximately how many after-hours trauma cases does your Ophthalmology Department perform per month?
a. $1-5$
b. $6-10$
c. $11-20$
d. $>20$

4. During after-hours eye trauma cases, approximately how often do you have access to eye-

trained operating room nurses?
a. Almost never
b. Infrequently
c. Frequently
d. Almost always

5. During after-hours eye trauma cases, approximately how often do you have access to a properly-functioning eye microscope?
a. Almost never
b. Infrequently
c. Frequently
d. Almost always

Fig. 1 Study questionnaire.

Adjusting for other factors, clinician satisfaction scores were 2.62 times higher for programs with access to eye-trained OR staff $(p<0.001)$ comparted to programs without those trained staff ( $\mathbf{-}$ Table 2 ).

The most commonly perceived barrier to a higher clinician satisfaction was reported as access to eye-trained OR staff $(28 / 57,49 \%)$, followed by none (19/57, 33\%), then access to proper materials and equipment $(7 / 57,12 \%)$, and finally access to a functional microscope $(2 / 57,4 \%)$.

\section{Discussion}

The surgical management of ophthalmic injuries is complex and requires specialized knowledge and equipment to be 
6. During after-hours eye trauma cases, approximately how often do you have access to all of your necessary eye materials and trays?
a. Almost never
b. Infrequently
c. Frequently
d. Almost always

7. What is your overall satisfaction with the efficiency and ease of coordination of after-hours eye trauma surgeries at your intuition $(1=$ lowest, $10=$ highest $)$ ?
a. 1
b. 2
c. 3
d. 4
e. 5
f. 6
g. 7
h. 8
i. 9
j. 10

8. What is the biggest barrier to a higher overall satisfaction with the efficiency and ease of coordination of after-hours eye trauma surgeries at your institution?
a. Difficulty accessing eye-trained OR nurses
b. Difficulty accessing a properly functioning eye microscope
c. Difficulty accessing proper eye-related materials and trays
d. No barriers

Fig. 1 (Continued)

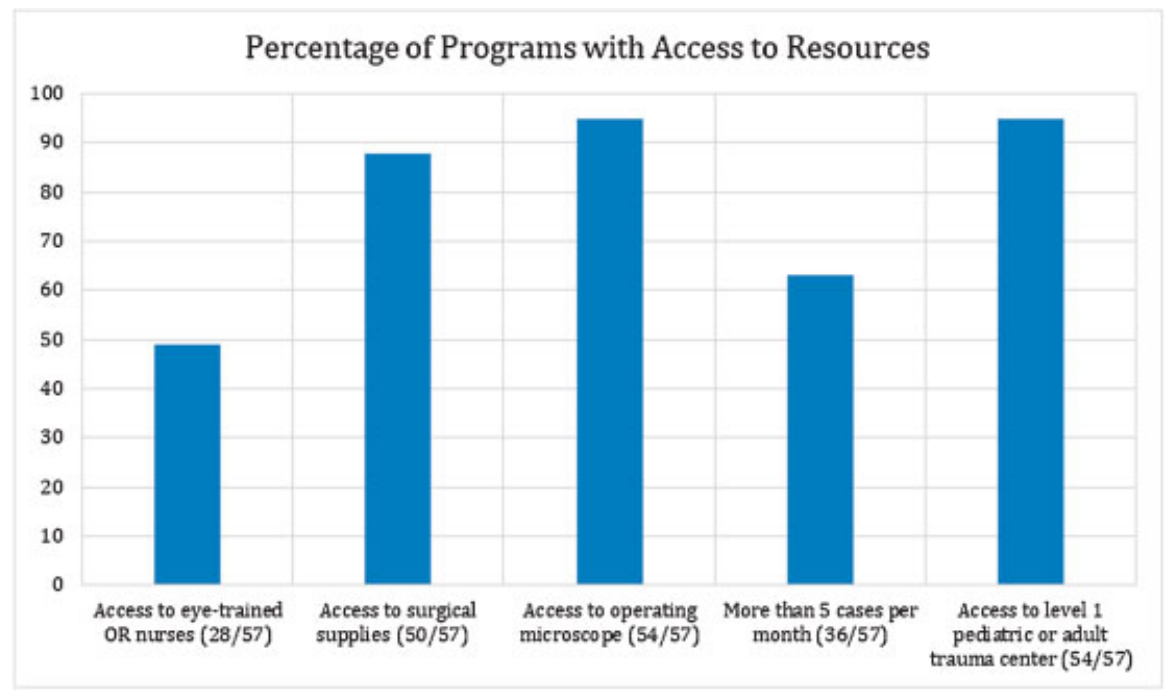

Fig. 2 Percentage of programs with access to resources. 
Table 1 A comparison of median clinician satisfaction scores by available resources

\begin{tabular}{|l|l|l|l|}
\hline Resource & Yes $^{\mathbf{a}}$ & No $^{\mathbf{a}}$ & $p$-Value $^{\mathbf{b}}$ \\
\hline $\begin{array}{l}\text { Access to eye-trained } \\
\text { OR staff }\end{array}$ & $8(7-9)$ & $5(4-6)$ & $<0.001$ \\
\hline $\begin{array}{l}\text { Access to surgical } \\
\text { supplies }\end{array}$ & $7(5-8)$ & $4(3-5)$ & $<0.001$ \\
\hline $\begin{array}{l}\text { Access to operating } \\
\text { microscope }\end{array}$ & $6.5(5-8)$ & $3(1-5)$ & 0.021 \\
\hline $\begin{array}{l}\text { More than 5 cases/ } \\
\text { month }\end{array}$ & $6(5-8)$ & $7(5-8)$ & 0.559 \\
\hline $\begin{array}{l}\text { Access to level 1 } \\
\text { trauma center }\end{array}$ & $6(5-8)$ & $9(5-10)$ & 0.194 \\
\hline
\end{tabular}

Abbreviation: OR, operating room.

${ }^{a}$ Median (interquartile range) for satisfaction scores are reported.

bp-Values were calculated using Wilcoxon's rank-sum.

'Either the pediatric or the adult facility was a level 1 trauma center.

performed efficiently. However, national regulations describing minimum criteria for adequate ophthalmological services at trauma centers are vague. In our study, we sought to gain a better understanding of how many programs have access to key resources during after-hours surgical cases, and how access to these resources affect clinician satisfaction.

Surveys have been successfully utilized to gather data regarding national trends in ophthalmology residency education, ${ }^{4,5}$ as well as in trends in compensation of retinopathy of prematurity screening. ${ }^{6}$ Ophthalmology listservs are a useful resource for distributing online surveys to clinicians to quickly gather data. ${ }^{4-6}$ To our knowledge, this is the first study to utilize an AUPO listserv surveying ophthalmology program directors regarding access to surgical resources

Table 2 Predictors of clinician satisfaction

\begin{tabular}{|c|c|c|c|c|}
\hline Measure & $\begin{array}{l}\text { Regression } \\
\text { coefficient }^{\mathrm{a}}\end{array}$ & p-Value & $\begin{array}{l}\text { Adjusted } \\
\text { coefficient }^{b}\end{array}$ & $p$-Value \\
\hline $\begin{array}{l}\text { Access to } \\
\text { eye-trained } \\
\text { OR staff }\end{array}$ & 2.99 & $<0.001$ & 2.62 & $<0.001$ \\
\hline $\begin{array}{l}\text { Access to } \\
\text { surgical } \\
\text { supplies }\end{array}$ & 3.11 & $<0.001$ & 1.85 & 0.005 \\
\hline $\begin{array}{l}\text { Access to } \\
\text { operating } \\
\text { microscope }\end{array}$ & 3.00 & 0.006 & 1.01 & 0.285 \\
\hline $\begin{array}{l}\text { More than } \\
5 \text { cases/month }\end{array}$ & -0.36 & 0.554 & 0.48 & 0.246 \\
\hline $\begin{array}{l}\text { Access to } \\
\text { level } 1 \text { trauma } \\
\text { center }^{c}\end{array}$ & -1.80 & 0.163 & -1.17 & 0.181 \\
\hline
\end{tabular}

Abbreviation: OR, operating room.

${ }^{a} p$-Values were calculated using generalized linear regression model.

${ }^{\mathrm{b}}$ Adjusted for eye-trained OR staff, surgical supplies, microscope, cases per month, and level 1 trauma center.

${ }^{{ }^{C}}$ Either the pediatric or the adult facility was a level 1 trauma center. after hours. This is also the first study to assess the relationship between clinician satisfaction and access to ophthalmic surgical resources. The survey response rate in our study was 57 out of 116 , or $49 \%$. This is comparable to the observed response rate in other studies utilizing an AUPO listserv for survey distribution (44-51\%).

In this study, frequent access to trained OR staff in the emergency setting seems to be the most important predictor of clinician satisfaction. Although access to eye-trained OR staff, a functioning microscope, and surgical supplies were all predictive of significantly higher clinician satisfaction scores, the majority of ophthalmology training programs have access to a functional microscope and adequate materials and equipment, whereas only half of all programs have after-hours access to OR staff with training to support ocular cases. Therefore, the area in which there may be potential to improve after-hours surgical infrastructure is the percentage of programs with access to such specialized OR staff. Furthermore, nearly all residency programs are linked to either an adult or pediatric level 1 trauma center, highlighting the importance of better defining minimum ophthalmology trauma service requirements.

There is evidence in the literature that the presence of specialized OR staff who are familiar with the surgical procedures being performed leads to improved outcomes. ${ }^{7-9}$ Similarly, surgical teams who display effective communication and teamwork have better surgical outcomes. A recent study by Mazzocco et al reported that teams that infrequently exhibit cooperative behaviors (such as confirmation of surgical plans, information sharing, inquiry for relevant information, mutual respect, and vigilance and awareness) are 4.8 times more likely to have their patients experience death or major complications. ${ }^{7}$

Literature from the nursing field also supports that OR nurses feel less safe working with unfamiliar surgical procedures. ${ }^{8,9}$ A recent survey conducted by a head OR nurse at the National University Hospital in Reykjavik, Iceland, highlighted the importance of adequate background knowledge during specialized procedures to anticipate proper resources and contribute to the case. ${ }^{8}$ In addition, a Finnish study interviewing OR nurses showed that when individuals were assigned to unfamiliar cases or surgeons, they experienced decreased effective communication and increased interpersonal conflict. ${ }^{9}$

Our study has several limitations: $49 \%$ of program directors completed the survey, so our results are not completely representative of all ophthalmology training programs. The decision to participate in the survey may be biased by selfselection. A multimodal approach including post mail, email, telephone, and face-to-face encounters may have resulted in a higher survey response rate. Second, much of the preparation for after-hours surgical cases is done by residents and fellows, whereas the survey queried only residency program directors. It is possible that trainee survey responses would differ based on dissimilarities in responsibilities. Third, our survey included only three variables, which were determined by an informal in-house survey at our own institution prior to this study. Thus, there are likely to be additional barriers 
encountered by other programs or individuals that we did not include in our survey. Including an "Other" free comment section would have allowed us to identify additional barriers.

In conclusion, while all three resources surveyed are important for high-quality surgical management, the vast majority of ophthalmology programs surveyed appear to have appropriate access to adequate surgical materials or a functioning microscope after hours. Based on our survey, increasing the availability of OR staff with the training to support complex ophthalmic surgery could potentially improve management of after-hours eye injuries at ophthalmology training programs. Further studies comparing clinical outcomes of after-hours ophthalmic surgery with and without eye-trained OR teams may provide further insight as to whether this resource should be considered a minimal requirement for optimizing the environment in which urgent ocular surgery is conducted.

\section{Funding}

Funding for this project was obtained from the Bucksbaum Institute for Clinical Excellence. The authors have no other financial disclosures or conflicts of interest.

\section{Conflict of Interest}

None declared.

\section{References}

1 Brophy M, Sinclair SA, Hostetler SG, Xiang H. Pediatric eye injuryrelated hospitalizations in the United States. Pediatrics 2006;117 (06):e1263-e1271

2 Channa R, Zafar SN, Canner JK, Haring RS, Schneider EB, Friedman DS. Epidemiology of eye-related emergency department visits. JAMA Ophthalmol 2016;134(03):312-319

3 American College of Surgeons Committee on Trauma. Resources for Optimal Care of the Injured Patient. Chicago, IL: American College of Surgeons; 2014. Available at: https://www.facs.org/ /media/files/ quality\%20programs/trauma/vrc\%20resources/resources\%20for \%20optimal\%20care.ashx

4 Braverman RS, Enzenauer RW. Socioeconomics of retinopathy of prematurity in-hospital care. Arch Ophthalmol 2010;128(08): 1055-1058

5 Lotfipour M, Rolius R, Lehman EB, Pantanelli SM, Scott IU. Trends in cataract surgery training curricula. J Cataract Refract Surg 2017;43(01):49-53

6 Coombs PG, Feldman BH, Lauer AK, Paul Chan RV, Sun G. Global health training in ophthalmology residency programs. J Surg Educ 2015;72(04):e52-e59

7 Mazzocco K, Petitti DB, Fong KT, et al. Surgical team behaviors and patient outcomes. Am J Surg 2009;197(05):678-685

8 Alfredsdottir H, Bjornsdottir K. Nursing and patient safety in the operating room. J Adv Nurs 2008;61(01):29-37

9 Silén-Lipponen M, Tossavainen K, Turunen H, Smith A. Potential errors and their prevention in operating room teamwork as experienced by Finnish, British and American nurses. Int J Nurs Pract 2005;11(01):21-32 